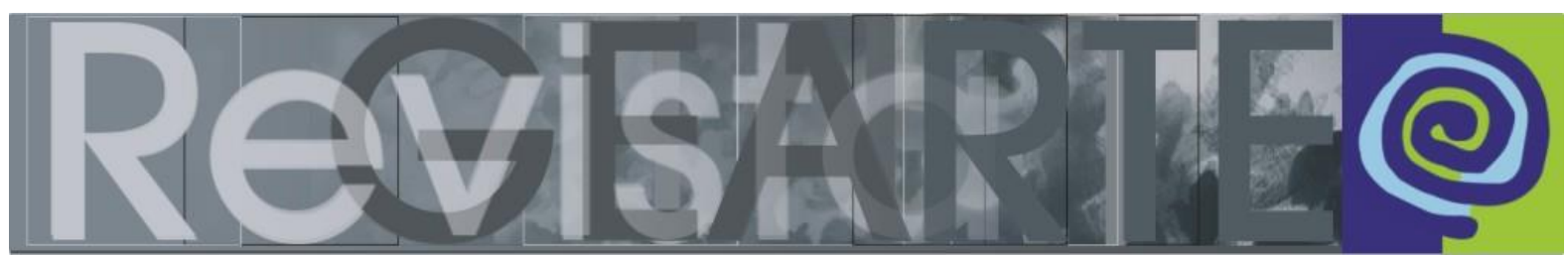

ISSN 2357-9854 | e-ISSN 2596-3198 (online)

\title{
Des/obediência docente na de/colonialidade da arte/educação na América Latina
}

\author{
Eduardo Junio Santos Moura \\ (Universidade Estadual de Montes Claros - \\ Unimontes, Montes Claros/MG, Brasil)
}

\begin{abstract}
RESUMO - Des/obediência docente na de/colonialidade da arte/educação na América Latina Neste debate, interessa apresentar algumas inquietações epistemológicas acerca da Arte/Educação na América Latina a partir do pensamento decolonial, propondo a desobediência docente como uma alternativa para a decolonialidade desse campo de conhecimentos. Trata-se, portanto, de pensar a opção decolonial no debate sobre as contradições e a hegemonia eurocêntrica/ estadunidense na Arte/Educação em contextos latino-americanos.
\end{abstract}

PALAVRAS-CHAVE

Arte/Educação. América Latina. Pensamento decolonial.

RESUMEN - Des/obediencia docente en la de/colonialidad del arte/educación en América Latina - En este debate, interesa presentar algunas inquietudes epistemológicas acerca del Arte/Educación en América Latina a partir del pensamiento decolonial, proponiendo la desobediencia docente como una alternativa a la decolonialidad de ese campo de conocimientos. Se trata, pues, de pensar la opción decolonial en el debate sobre las contradicciones y la hegemonía eurocéntrica/ estadunidense en el Arte/Educación en contextos latinoamericanos.

PALABRAS CLAVE

Arte/Educación. América Latina. Pensamiento decolonial.

Nesta mesa, interessa apresentar algumas inquietações epistemológicas acerca da Arte/Educação na América Latina a partir do pensamento decolonial ${ }^{1}$, propondo a desobediência docente como uma alternativa para a decolonialidade desse campo de conhecimentos. Trata-se, portanto, de pensar a opção decolonial no debate sobre as contradições e a hegemonia eurocêntrica/ estadunidense na Arte/Educação em contextos latino-americanos.

O ponto de partida de tais inquietações está na "colonialidade do poder", do saber e do ser na América Latina, de que trata o sociólogo peruano Aníbal Quijano

1 Para Catherine Walsh, a supressão do "s" e o uso do termo "decolonial" não se trata de promover um anglicismo, ao contrário, marca uma distinção com o significado em castelhano do "des" como negação. A intelectual aponta que não pretende simplesmente "desarmar, desfazer ou reverter o colonial" como se fosse possível passar de um momento colonial a outro não-colonial. Nesse caso, a intenção é demarcar e provocar uma postura e atitude contínua de "transgressão, intervenção, insurgência e incisão". Assim, o decolonial assume um caminho de luta contínua (WALSH, 2009, p. 14-15). 


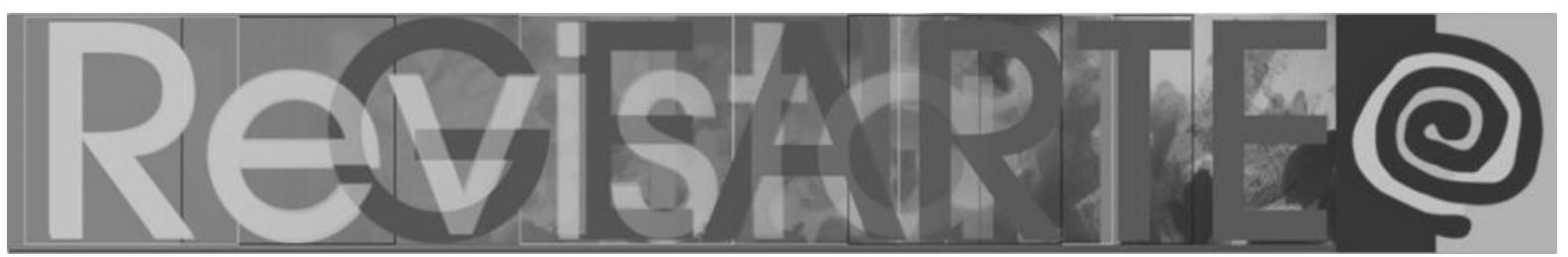

(2007, 2005, 1992), a qual, refletida na arte, na educação, nas academias, nos cursos/currículos e nos processos de formação docente em arte e, consequentemente na Arte/Educação, privilegia uma matriz de conhecimentos eurocêntrica/ estadunidense e deslegitima outros saberes e outras artes, especialmente as latino-americanas.

A desobediência docente, aqui referida como uma alternativa para pensar a decolonialidade da Arte/Educação na América Latina, encontra suas bases no que o semiótico argentino Walter Mignolo $(2010,2008)$ chama de "desobediência epistêmica". Assim, "desobediência docente" (MOURA, 2018) só faz sentido se for epistêmica e mira a decolonialidade intelectual de formadores/as para a docência em arte.

O centro das inquietações que trago está na uni-versalidade ${ }^{2}$, ou seja, uma única versão: europeia/estadunidense para a produção de conhecimentos e as impossibilidades de produção de saberes desde outras histórias, outras culturas, outras artes, excluídas pela visão hegemônica. Assim, inquietam-me as questões epistemológicas acerca da Arte/ Educação na América Latina.

\section{Colonialidade do poder (do saber e do ser) como ponto de partida}

"Colonialidade" é um conceito criado pelo sociólogo peruano Aníbal Quijano no final da década de 1980 e início da década de 1990 e aparece em seus escritos no texto intitulado "Colonialidad y modernidad/racionalidad", no qual o autor aponta que a colonialidade é "el modo mas general de dominación en el mundo actual, una vez que el colonialismo como orden político explícito fue destruído" (QUIJANO, 1992, p. 14). Importa compreender que o autor não está dizendo que o colonialismo europeu foi superado na América Latina nem no mundo. É preciso compreender ainda que o autor expõe as transformações estratégicas do colonialismo para sua manutenção pela colonialidade. A Europa posicionada no centro do sistema-mundo moderno opera por meio dos mecanismos de controle colonial, o que Quijano (2007) chama de "colonialidade do poder":

2 Utilizo os termos "uni-versalidade" e "uni-versal" para referir-me à ideia de versão única dos fatos históricos: europeia/estadunidense. 


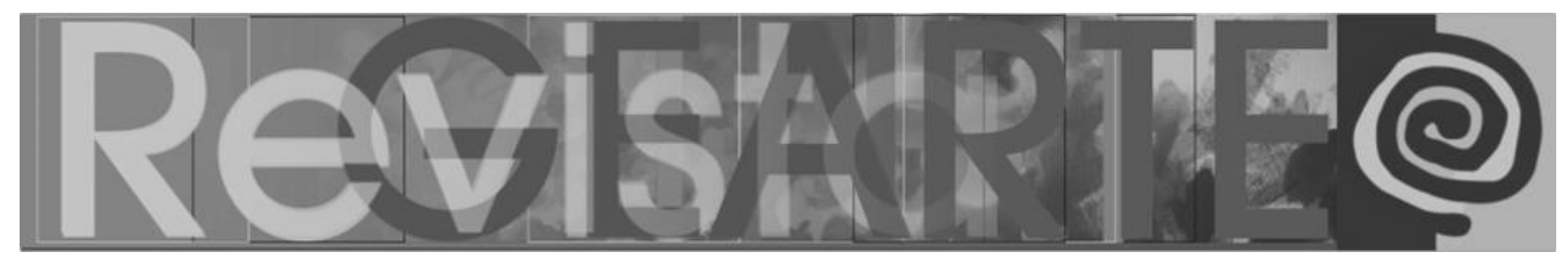

Tal como lo conocemos históricamente, el poder es un espacio y una malla de relaciones sociales de explotación/ dominación/ conflicto articuladas, básicamente, en función y en torno de la disputa por el control de los siguientes ámbitos de existencia social: (1) el trabajo y sus productos; (2) en dependência del anterior, la "naturaleza" y sus recursos de producción; (3) el sexo, sus productos y la reproducción de la especie; (4) la subjetividad y sus produtos materiales e intersubjetivos, incluido el conocimiento; (5) la autoridad y sus instrumentos, de coerción en particular, para asegurar la reproducción de ese patrón de relaciones sociales y regular sus câmbios. (QUIJANO, 2007, p. 96).

A partir do conceito de colonialidade do poder em Quijano, Mignolo explora a relação da colonialidade com a modernidade e aponta que "a colonialidade é constitutiva da modernidade - não há modernidade sem colonialidade" (MIGNOLO, 2017, p. 2). O autor aponta ainda que a "colonialidade é o lado escuro da modernidade" prometida pela Europa e que nunca chegou à América Latina, porque foi inventada como estratégia de dominação.

O uso do termo "colonialidade" aqui corrobora o pensamento decolonial do Grupo Modernidade/ Colonialidade ${ }^{3}$ e refere-se então à presença/manutenção da matriz colonial de poder na contemporaneidade, o que, no entender do escritor ganês Kwame Nkruma (1965), trata-se de "neocolonialismo", ou seja, a tentativa moderna de perpetuar o colonialismo.

Para Nelson Maldonado-Torres (2007, p. 131), o colonialismo "denota una relación política y económica, en la cual la soberanía de un pueblo reside en el poder de otro pueblo o nación, lo que constituye a tal nación en un império", diferente da ideia de colonialidade que se refere a "un patrón de poder que emergió como resultado del colonialismo moderno" e mais expandido se refere à forma como "el trabajo, el

3 O Grupo Modernidade/Colonialidade (M/C) é um coletivo de intelectuais latino-americanos que revisam a epistemologia das ciências sociais e humanidades na região. O grupo associa: o filósofo argentino Enrique Dussel, o sociólogo peruano Aníbal Quijano, o semiólogo e teórico cultural argentino Walter Mignolo, a socióloga-pedagoga norte-americana radicada no Equador Catherine Walsh, o filósofo porto-riquenho Nelson Maldonado-Torres, o sociólogo porto-riquenho Ramón Grosfoguel, o antropólogo colombiano Arturo Escobar, dentre outros (WALSH, OLIVEIRA, CANDAU, 2018). 


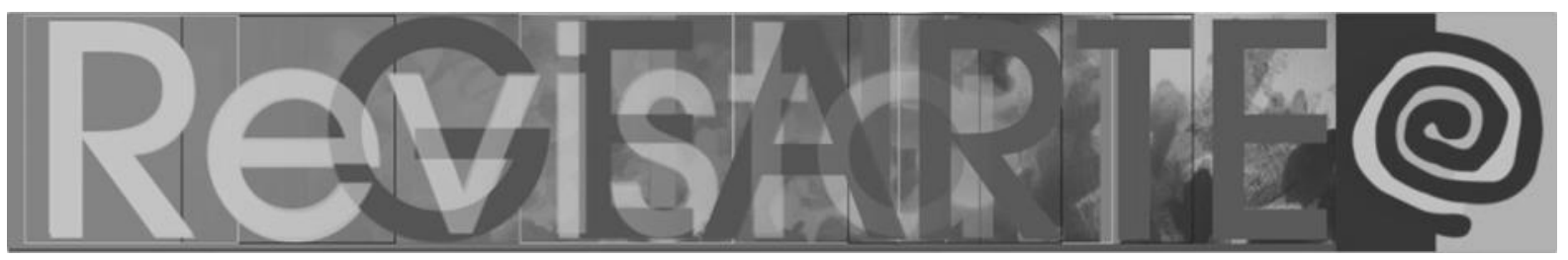

conocimiento, la autoridade y las relaciones intersubjetivas se articulan entre sí, a través del mercado capitalista mundial y de la idea de raza" (idem).

O colonialismo entranhado nas mais diversas esferas da sociedade contemporânea é sustentado pela colonialidade que imprime na América Latina suas marcas nas formas de conhecer, criar e viver. O cerne da lógica da colonialidade é discutido por Quijano (2005, p. 107) quando considera a constituição da América Latina como "primeiro espaço/tempo de um padrão de poder de vocação mundial". A ideia de raça, segundo o estudioso, foi o argumento que legitimou as relações de dominação do conquistador sobre o conquistado, e o capitalismo, como nova estrutura de controle do trabalho, articula os processos de exploração e expropriação, incluindo a escravidão e a servidão.

Esse padrão de poder, além de garantir a exploração de uns seres humanos por outros em escala mundial, cria subalternizações de experiências de vida e hierarquizações de conhecimentos que reproduzem as relações de dominação e mantêm abertas as feridas coloniais, que seguem profundas, infectadas e sangrando.

\section{Desobediência epistêmica e (re)pensamento crítico}

As feridas abertas pelo eurocentrismo, excludente e hegemônico, estão latentes no pensamento latino-americano. Nesse território, o pensar, seja ele, artístico, social, político, histórico, filosófico, antropológico etc, passa pela Europa, o que leva a questionar: e antes da invasão, como pensavam os povos autóctones? Era possível pensar? São possíveis hoje outras formas de (re)pensar o mundo? É possível (re)pensar o mundo desde a América Latina e de suas realidades?

Não se trata de excluir uma forma de pensar e substituí-la por outra. Trata-se de incluir outras formas de pensar. Não se trata de criar novas periferias e novos centros. Trata-se de (re)pensar criticamente a colonialidade intelectual que opera sobre as epistemes latino-americanas. 


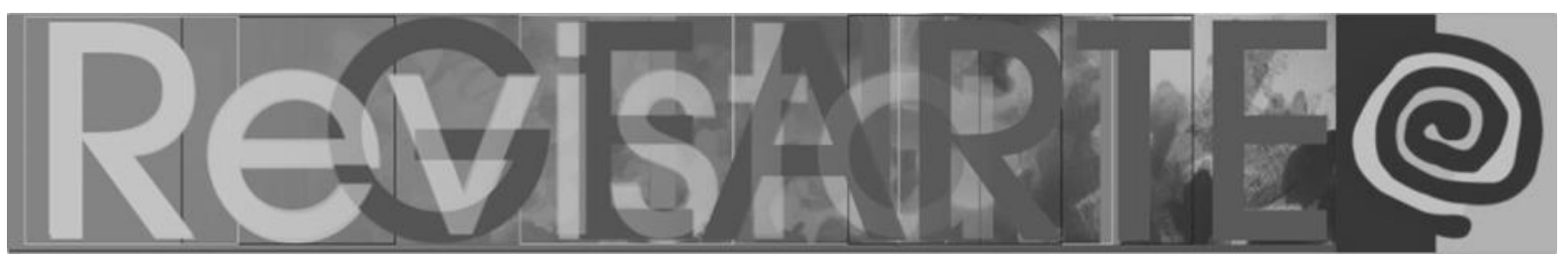

Ana Mae Barbosa (2016, p. 08), explorando e expondo, de forma irônica, o que chama de "colonialismo intelectual" que impera no campo da educação em geral, na Arte/educação e na formação docente em arte, critica os modismos que invadem os campos artístico e educacional com fácil penetração, bastando que venham de homens brancos heterossexuais, da Europa ou dos Estados Unidos, e aponta como esses campos se submetem, sazonalmente: "na moda de inverno Perrenoud para acompanhar o frio do capitalismo explorador; na primavera Larrosa para curtir a experiência e na moda verão, leve e solta, Rancière".

O grupo M/C apresenta alguns caminhos como forma de (re)pensamento crítico em contraponto às grandes narrativas modernistas europeias ao desafiar a geopolítica do conhecimento e localizar questionamentos nas bordas dos sistemas de pensamento e investigações, possibilitando modos de pensamento não-eurocêntrico. O pensamento compartilhado pelo grupo pauta-se na coexistência de diferentes epistemes, as quais colocam em xeque o desenho colonial da geopolítica do conhecimento e a subalternização epistemológica que esse modelo promove. $\mathrm{O}$ (re)pensamento crítico decolonial, nos processos de produção de conhecimentos, trata de romper com os uni-versalismos alienantes e traz à pauta os binarismos modernos que inundam as academias: norte/sul, ocidente/oriente, colonizador/colonizado, rico/pobre, alta cultura/baixa cultura, branco/negro, homem/mulher, ciência/arte. Por outras vias, trata-se de pensar co-existências: de culturas, de povos, de ciências, de artes, de pensamentos, problematizando as hierarquias (artísticas, territoriais, raciais, epistemológicas), legitimando processos anti-hegemônicos de produzir conhecimentos.

O pensar decolonial, segundo Mignolo (2007), não implica "deslegitimar", mas "ultrapassar os limites" das teorias eurocêntricas (marxismo, freudismo, lacanianismo, foucaultianismo etc.) e legitimar outras teorias e outras práticas não-eurocêntricas. $O$ sentido decolonial implica pensar a partir das categorias não incluídas nos fundamentos do pensamento ocidental; implica legitimar formas de pensar e conhecer gestadas apesar dos silenciamentos/apagamentos teóricos e da inferiorização de 


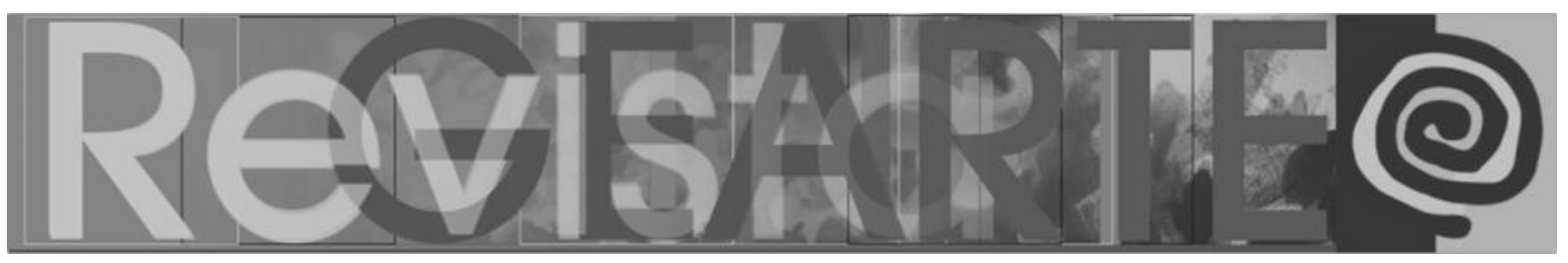

pensadores e pensadoras de contextos não-europeus, especialmente da América Latina.

Pensar epistemo-diversidades pressupõe reconhecer que o colonialismo legou aos colonizados uma dominação epistemológica que produziu relações desiguais de saber/poder, cujo resultado foi uma forma opressora de saber que relegou muitos outros saberes à subalternidade.

O filósofo argentino Enrique Dussel ajuda a compreender, em parte, o emaranhado de relações tecidas pelos processos colonizadores, especialmente quando reflete sobre como operou a (re)produção da visão de superioridade/legitimidade do pensamento europeu e a inferiorização/deslegitimação, construída por essa mesma visão, sobre outras formas de pensar. Para Dussel (2005, p. 27), "esta Europa Moderna, desde 1492, 'centro' da História Mundial, constitui, pela primeira vez na história, a todas as outras culturas como sua 'periferia'”. O autor apresenta o que chama de "estrutura centro-periferia do sistema mundial", em que "todas as outras culturas periféricas" (América Latina, África, Ásia) derivam de uma cultura central que é a Europa Moderna.

Desse ponto, é possível pensar que, para o europeu, o problema da inferioridade reside no outro e, nesse sentido, tudo que está no outro, que venha do outro - considerado bárbaro, iletrado, despadronizado, cópia imperfeita, não-humano, desalmado, descivilizado - não pode ser legítimo, é inferior, é de segunda categoria. Isso move um desejo de virar o espelho e fazê-lo refletir para o europeu, levando-o a perceber que o problema não reside no outro, mas na visão que ele tem do outro, ou seja, o problema está no Eu do Eu-ropeu. O problema reside na visão de que a Europa é o centro do mundo e do poder; visão legitimada pelo capital e pelo capitalismo.

\section{De/colonialidade da Arte/Educação}

Pensar uma Arte/Educação decolonial não implica deslegitimar, nesse campo, os conhecimentos em arte de matriz europeia (diferente de uma perspectiva eurocêntrica); implica, necessariamente, legitimar os saberes em arte de matriz latino- 


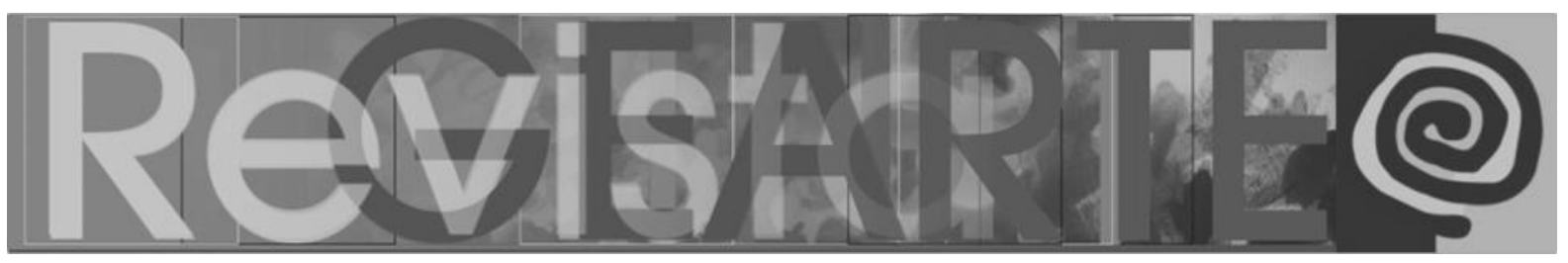

americana. Destarte, trata-se do que Mignolo $(2010,2007)$ chama "opção decolonial". Para o mesmo autor, "El pensar descolonial exige un vuelco epistémico y la afirmación del "ser donde se piensa" en lugar de "saber que se existe porque se piensa" (MIGNOLO, 2010, p. 92). Demanda o reconhecimento de um passado colonial, sua compreensão histórica desde o lugar de enunciação e, pela consciência política, potencializando questionamentos e ações anti-hegemônicas e anti-hierárquicas em favor do pensar/fazer/ser/sentir decolonial pela Arte/Educação.

Encontra-se no pensamento de Ana Mae Barbosa, desde a década de 1980, inúmeras referências ao que pode ser compreendido como uma visão de Arte/Educação decolonial; portanto não é nenhuma novidade. A educadora pioneira da Arte/Educação brasileira o é também em pensar esse campo de conhecimentos por um viés anti-colonialista e decolonial. A ideia de Arte/Educação no pensamento da autora se contrapõe às anemias teórico/práticas e metodológicas da 'Educação Artística'. O termo, em si, já aponta para uma perspectiva decolonial ou, pelo menos, para o que Barbosa (1998, p. 32) chama de "perturbação da consciência colonizada". A autora trata de pensar a cultura e o ensino de arte pela "necessidade de reconhecer a si próprio" como uma "necessidade básica de sobrevivência e de construção da sua própria realidade" e chama a atenção para o domínio da educação nos países do chamado "Terceiro Mundo ocidental" pelos "códigos culturais europeus" e, mais recentemente, pelo "código cultural norte-americano" (BARBOSA, 1998, p. 14).

O domínio dos códigos culturais europeus está presente desde a invasão e conquista de Abya Yala ${ }^{4}$ por homens-brancos-heterossexuais-europeus até a contemporaneidade. Seja através de relatos escritos, orais ou visuais, as imagens projetadas desse contexto e sobre esse contexto, representam os ideais artísticos, estéticos, culturais, éticos e políticos do colono; compõem a edificação histórica pela lente colonizadora que exclui tudo o que não esteja nos moldes europeus,

4 ABYA YALA: na língua do povo Kuna, significa Terra madura, Terra Viva ou Terra em florescimento e é sinônimo de América. Abya Yala vem sendo usada como uma autodesignação dos povos originários do continente em contraponto à América. Fonte: Carlos Walter Porto-Gonçalves em: Chakaruna: Abya Yala sin fronteras. Disponível em: <https://goo.gl/3pFwc9> 


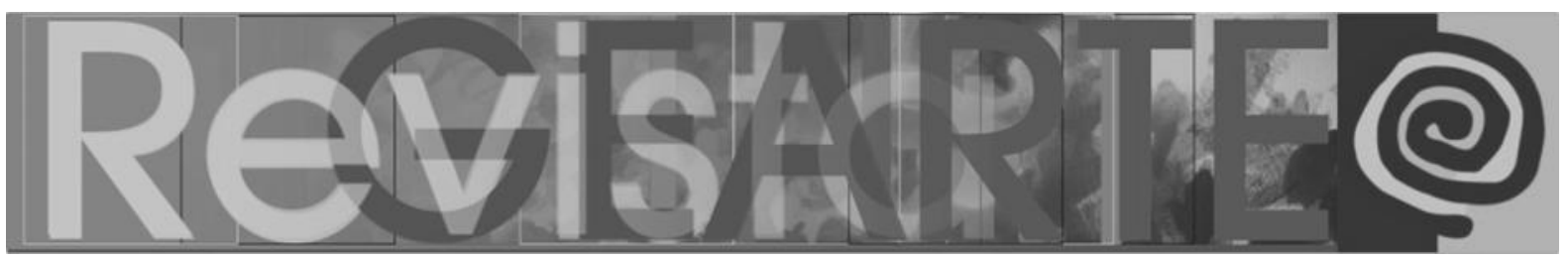

construindo, como aponta Santiago Castro-Gómez (2005, p. 81), “um funil no qual só passarão aquelas pessoas cujo perfil se ajuste ao tipo requerido pelo projeto da modernidade: homem, branco, pai de família, católico, proprietário, letrado e heterossexual".

Desde os relatos de Américo Vespúcio e Cristóvão Colombo, nos séculos XV e $\mathrm{XVI}$, encadeia-se um relacionamento, tanto dos povos americanos quanto de uma visão uni-versal do Velho Mundo, com imagens produzidas em vínculos de decadência, desumanidade e monstruosidade, as quais refletem o que o colonizador quer mostrar, pois são produzidas pela episteme hegemônica.

Pensar por esse prisma conduz à compreensão da dimensão artística (visual/imagética) a par das dimensões religiosas (catolicismo) e de linguagem/idioma (português e espanhol), operando como uma das mais profícuas formas de manutenção do projeto moderno/colonial e da hegemonia eurocêntrica nos contextos latino-americanos, o que repercute nos mais diversos campos e, estrategicamente, no campo educacional. A composição imagética da América Latina distorcida pelo espelho do colonizador, desde o renascimento europeu, converteu-se em verdade universal e contribuiu para as abjeções, as negações, as violações, os encobrimentos e os apagamentos epistemicidas das histórias, das artes e das culturas latinoamericanas na Arte/Educação, impossibilitando vislumbrar os reflexos das imagens do que realmente representa esse território.

Há uma construção narrativa por imagens que contribui para perpetuar as heranças coloniais e deserdar outras epistemes, a qual impregnaram olhares e deu aparência natural ou necessária à civilização/modernização através de atrocidades como a escravização de índios e de negros por toda a América Latina. O poder da imagem, de fixar nas mentes as ideias e os ideais europeus, foi explorado com grande competência pelo chamado primeiro mundo, de forma que até hoje os referenciais, sejam de bom ou de belo, remetem ao que é externo e, quase nunca, ao que é próprio. 


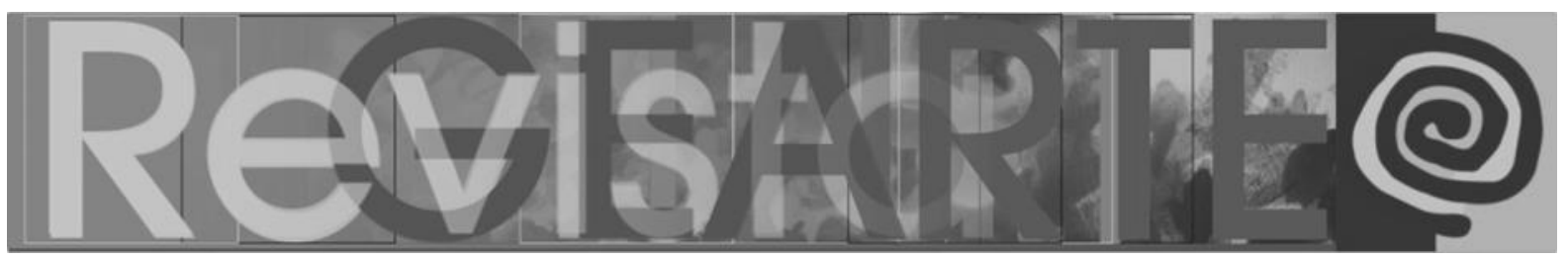

Aproximando essa mirada ao campo da Arte/Educação, vejo-o como um campo de conhecimentos explorado para a reprodução dos ideais opressores do colonizador, um campo em que a matriz colonial de poder ganha legitimidade, é sustentada e mantida pelas estratégias da colonialidade do poder, do ser e do saber. Direciono meu olhar para espaços de ações arte/educadoras e observo que se erigiu uma cegueira em relação às expressões artísticas, aos/às produtores/as e à produção artística latinoamericana - não exclusivamente visual - e uma consequente ausência destes/as entre os conteúdos a serem ensinados/aprendidos nas aulas de arte. Observo que essa cegueira contribui para o desconhecimento das histórias, das culturas e das expressões artísticas latino-americanas como representações identitárias, mestiças, dos povos dessa região, a partir das heranças indígenas e negras, híbridas indo-americanas e afro-americanas suplantadas pelos códigos culturais europeus e de seus herdeiros euro-norteamericanos, especialmente estadunidenses.

A episteme eurocêntrica/ estadunidense, única e excludente, desde a constituição das primeiras universidades latino-americanas e na (con)formação docente em muitas instituições, até a contemporaneidade, é responsável pela homogeneização das formas de produzir conhecimento e de conhecer, de tal forma que a única versão de arte ensinada e aprendida nos espaços educativos é proveniente dessa matriz. As imagens que compõem os repertórios, os imaginários e os saberes docentes são europeias/estadunidenses.

É desassossegador pensar que parece não existir, sequer, um questionamento sobre essa hegemonia por parte tanto de formadores/as quanto de formandos/as para docência em arte. Tal hegemonia nas formas de pensar e de produzir o ensino/aprendizagem de arte fazem pouco ou nenhum sentido/ significado para o (re)conhecimento das realidades artística, histórica, social, política ou cultural latinoamericanas. Há um predomínio nos espaços educativos brasileiros, sejam eles formais ou não-formais, de um (único) ensino de arte, de matriz eurocêntrica/ estadunidense, que opera de forma neocolonial, reprodutivista, acrítica e apolítica (no sentido da falta de consciência política), que é reflexo de uma formação docente na mesma perspectiva.

MOURA, Eduardo Junio Santos. Des/obediência docente na de/colonialidade da arte/educação na América Latina. 321 Revista GEARTE, Porto Alegre, v. 6, n. 2, p. 313-325, maio/ago. 2019.

Disponível em: http://seer.ufrgs.br/gearte 


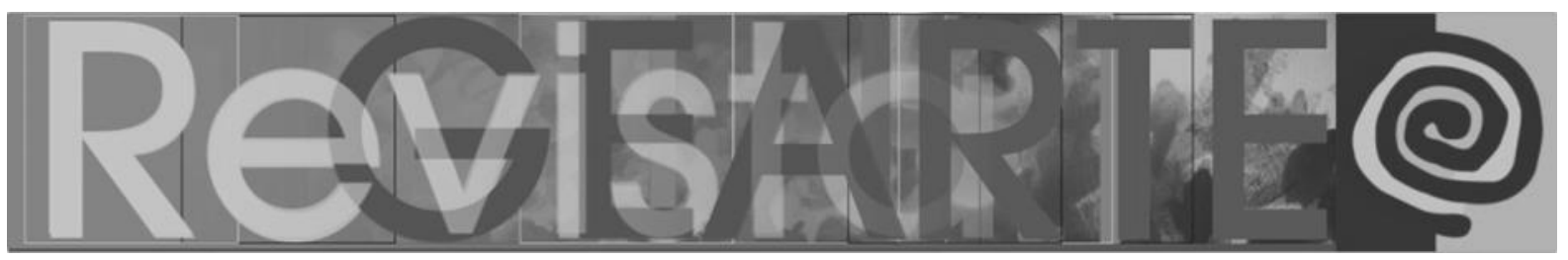

O desafio de pensar ensinos/aprendizagens de arte pela opção decolonial implica produzir saberes, desde a formação inicial docente em arte, a partir de outras epistemes e, pela via antropofágica/canibal, deglutir os códigos que não refletem a imagem do que é a América Latina, na busca pela legitimação das imagens que representam esse território.

\section{Opção decolonial e a desobediência docente como alternativa}

Segundo Mignolo (2010), "a matriz colonial de poder é o conceito chave da opção decolonial”, ou seja, há que se reconhecer que essa matriz existe e compreender como ela opera para fazer a opção decolonial. Ainda, compreender que o pensar decolonial não implica a deslegitimação de outras formas de pensar. 0 pensamento decolonial é inclusivo.

Quando penso nos apagamentos e nas invisibilizações das expressões artísticas e dos/as artistas latino-americanos/as entre os conteúdos do campo de conhecimentos Arte, nos diversos espaços educativos, como consequência do encobrimento dessas expressões nos currículos dos cursos de formação docente em Arte, início um refazimento dos trajetos que produziram esses silenciamentos. Nesse percurso, caminho por territórios de conhecimentos que o projeto moderno/colonial europeu fragmentou como por exemplo Arte e Ciência, limitando a uma única versão, uma única forma de pensar. Desse ponto começo a questionar: Qual o sentido de formar docentes em arte na América Latina com referenciais que privilegiam a arte, a cultura e a história europeias? Logo, é possível questionar: Qual o sentido de uma Arte/Educação que privilegia uma matriz de conhecimentos eurocêntrica na América Latina? Tais questões direcionam para uma visão de eurocentrismo não como espaço ou localização geográfica, mas como forma de pensar que se impõe como única, verdadeira e universal. Nessa perspectiva, dado o eurocentrismo impregnado nas academias e nos currículos dos cursos de formação, observo, na América Latina, não somente uma hegemonia dessa forma de pensar e fazer a formação docente em arte, mas também uma versão única de ensino/aprendizagem de arte, decorrente da reprodução via colonialidade. 


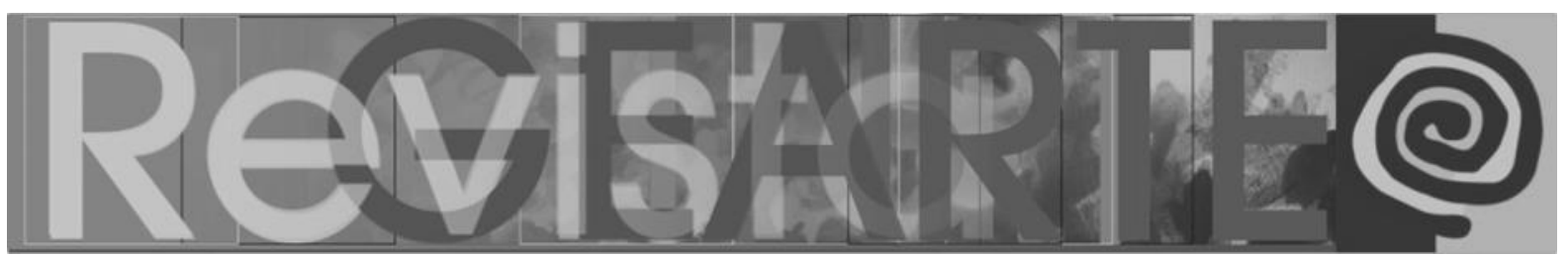

O discurso falacioso e homogeneizante de que "não há hoje como se reconhecer pertencente a um lugar, face à globalização", é mais uma estratégia que desterritorializa e cria a falsa ideia de "cidadão do mundo", aquele que é do mundo e, ao mesmo tempo, não pertence a lugar nenhum. A ideia de não-lugar, nesse contexto, cria a ilusão de que não é preciso se identificar com nenhuma cultura específica, pois "o mundo globalizado é o seu lugar", "é lugar de todos". Diga-se isso ao europeu em tempos de massas de refugiados. Diga-se ao europeu: Não há motivo para se identificar com uma cultura francesa, italiana, alemã, portuguesa, espanhola, pois o mundo é o seu lugar.

A globalização, a serviço do sistema-mundo capitalista, tendo a Europa como centro do poder, encobre outras culturas, mas mantém viva a Europa como divindade de onde provém o conhecimento e a cultura uni-versal. Afirmo que não existe globalização que legitime epistemes latino-americanas, africanas, asiáticas ou mesmo que evidencie essas culturas em cenários globais. A ideia de globalização, tal como a de modernidade, é invenção europeia, é estratégia colonial.

Na contramão da hegemonia eurocêntrica nas formas de pensar e de produzir a formação docente em contextos latino-americanos, é que penso uma 'desobediência docente' em processos de formação de professores/as de arte. Tal proposição implica pensar a formação docente pela opção decolonial como forma de problematizar as hierarquizações que legitimam uma episteme eurocêntrica e deslegitimam a formação com base nos saberes desde as artes e as culturas latino-americanas. Compreendo o (re)pensamento crítico sobre a América Latina, sobre sua história colonial e sobre as heranças legadas pelos 'ismos' (colonialismo, patriarcalismo, capitalismo), desvelados pela arte, pelas histórias e pelas culturas latino-americanas, como um caminho que possibilita decolonizar as formas de pensar/ ser/ fazer/ sentir nesse território.

A desobediência docente de que trato não se limita a conhecer arte latinoamericana ou inserir no currículo dos cursos de formação docente em arte componentes curriculares, referências bibliográficas ou conteúdos de arte latinoamericana; vai além: reclama uma desobediência docente que só fará sentido se for 


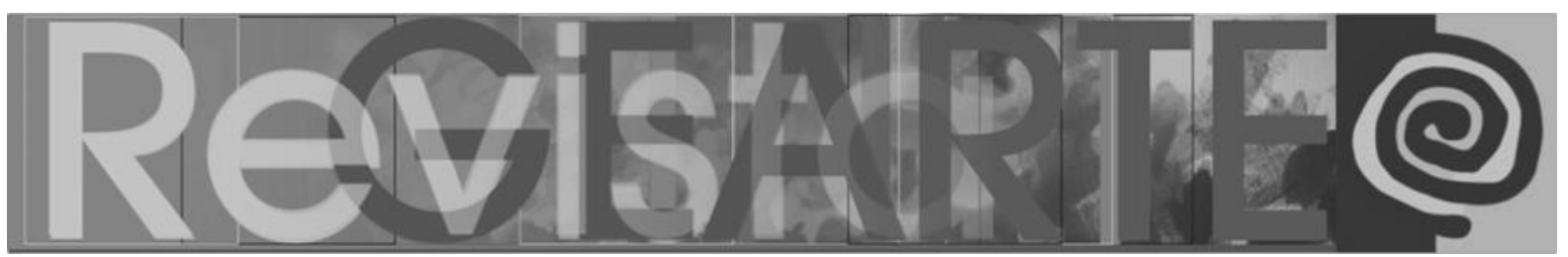

epistemológica que, para Mignolo $(2010,2008)$, implica "aprender a desaprender para reaprender". A desobediência docente demarca e dá contornos a uma produção de conhecimentos em arte, a partir da formação inicial dos/das professores/as até os processos educativos em arte que legitimem epistemes anti-hegemônicas, nãoeurocêntricas; que criem identificação com a América Latina nas dimensões artísticas, históricas, sociais, culturais, políticas, éticas, estéticas; e ampliem o espectro para uma consciência decolonizada.

A desobediência docente precisa partir da decolonialidade intelectual de formadores e formadoras de professores e professoras de arte e ser impressa nos currículos dos cursos de formação. A decorrência é a possibilidade de pensar uma Arte/Educação decolonial, que passa a refletir as potencialidades do pensamento artístico e as expressões artísticas latino-americanas na produção de consciências cidadãs também decolonizadas.

A ideia de desobediência docente deve ser pensada ainda como uma edificação cujo alicerce sejam os/as docentes em arte, mas não exclusivamente, capazes de imprimir as marcas de um projeto decolonizador das formas de pensar arte/ conhecer arte/ fazer arte, cujos olhares se voltem às realidades latinoamericanas, ao invés de aquiescer a legitimação de uma história única: ocidentaleuropeia-estadunidense.

\section{Referências}

BARBOSA, Ana Mae. Tópicos utópicos. Belo Horizonte: C/Arte, 1998.

BARBOSA, Ana Mae. Arte/Educação: formando professores. Revista CLEA (Consejo Latinoamericano de Educación por el Arte). n. 2, p. 7-29, 2016. Disponível em: <https://goo.gl/ANGNny> Acesso em: 03 fev. 2019.

CASTRO-GÓMEZ, Santiago. Ciências sociais, violência epistêmica e o problema da invenção do outro. In: LANDER, Edgardo (Org.). A colonialidade do saber: eurocentrismo e ciências sociais. Perspectivas latinoamericanas. Colección Sur Sur, CLACSO, Ciudad Autónoma de Buenos Aires, Argentina, 2005. p. $80-87$

DUSSEL, Enrique. Europa, Modernidade e Eurocentrismo. In: LANDER, Edgardo (Org.). Colonialidade do saber: eurocentrismo e ciências sociais. Perspectivas latino-americanas. CLACSO, Ciudad Autónoma de Buenos Aires, 2005. p. 24-32

MALDONADO-TORRES, Nelson. Sobre la colonialidad del ser: contribuciones al desarrollo de un concepto. In: CASTO-GOMEZ, Santiago; GROSFOGUEL, Ramón (Orgs.). El giro decolonial: 


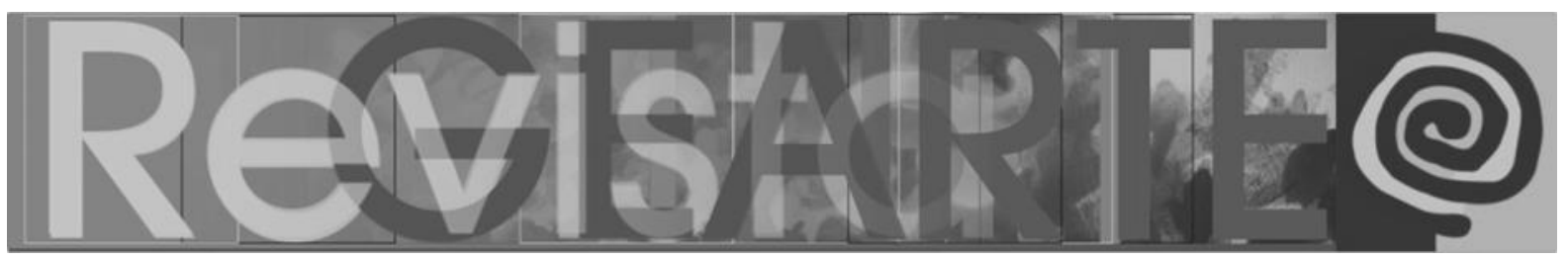

reflexiones para una diversidad epistémica más allá del capitalismo global. Bogotá: Siglo del Hombre Editores; Universidad Central, Instituto de Estudios Sociales Contemporáneos y Pontificia Universidad Javeriana, Instituto Pensar, 2007. p. 127-168

MIGNOLO, Walter. La idea de América Latina: la herida colonial y la opción decolonial. Barcelona: Gedisa, 2007.

MIGNOLO, Walter. Desobediência epistêmica: a opção descolonial e o significado de identidade em política. Cadernos de Letras da UFF - Dossiê: Literatura, língua e identidade, n. 34, p. 287-324, 2008.

MIGNOLO, Walter. Desobediencia epistémica: retorica de la modernidad, lógica de la colonialidad y gramática de la descolonialidad. Ciudad Autónoma de Buenos Aires: Ediciones Del Signo, 2010.

MIGNOLO, Walter. Colonialidade: O lado mais escuro da modernidade. Trad. Marco Oliveira. Revista Brasileira de Ciências Sociais RBCS, v. 32, n. 94, p. 1-18, jun., 2017.

MOURA, Eduardo Junio Santos. Des/obediência na de/colonialidade da formação docente em Arte na América Latina (Brasil/Colômbia). 2018. 249f. Tese (Doutorado em Educação) - Faculdade de Educação, Universidade Federal de Minas Gerais, Belo Horizonte.

NKRUMAH, Kwame. Neocolonialism: the last stage of imperialism. London: Thomas Nelson \& Sons Ltd., 1965. Disponível em:https://goo.gl/bsD4sF Acesso em: 10 mar. 2019.

QUIJANO, Aníbal. Colonialidad y modernidad/racionalidad. Peru Indígena, v. 13, n. 29, p. 11-20, 1992.

QUIJANO, Aníbal. Colonialidade do Poder, Eurocentrismo e América Latina. In: LANDER, Edgardo (Org.). A colonialidade do saber: eurocentrismo e ciências sociais. Perspectivas latinoamericanas. Colección Sur Sur. Ciudad Autónoma de Buenos Aires, Argentina: CLACSO, 2005.

QUIJANO, Aníbal. Colonialidad del poder y clasificación social. In: CASTRO-GOMEZ, Santiago; GROSFOGUEL, Ramon (Coords.). El giro decolonial: reflexiones para una diversidad epistêmica más allá del capitalismo global. Bogotá: Siglo del Hombre Editores; Universidad Central, Instituto de Estudios Sociales Contemporáneos, Pontificia Universidad Javeriana, Instituto Pensar, 2007. p. 93-126

WALSH, Catherine. Interculturalidad crítica y educación intercultural. In: Seminario Interculturalidad y Educación Intercultural. La Paz: Instituto Internacional de Integración del Convenio Andrés Bello, 2009.

\section{Eduardo Junio Santos Moura}

Doutor em Educação pela Universidade Federal de Minas Gerais (doutorado Latino-americano/ FaE/ UFMG) com período sanduíche na Universidad Pedagógica Nacional (UPN), sede Bogotá (Colômbia), Mestre em Educação (UnB), Especialista em História da Arte (Unimontes), Graduado em Educação Artística/ Artes Plásticas (Unimontes). Professor da Licenciatura em Artes Visuais do Departamento de Artes da Universidade Estadual de Montes Claros (Unimontes). Pesquisa em/sobre ensino de Arte, processos pedagógicos no ensino de Artes Visuais. Publicação em livro: Iniciação à docência: processos formativos no PIBID/ Unimontes.

E-mail: eduardomourarte@yahoo.com.br

ORCID: https://orcid.org/0000-0003-1215-5731

Currículo Lattes: http://lattes.cnpq.br/5748883453897957

Recebido em 12 de fevereiro de 2019

Aceito em 30 de março de 2019 